\title{
Urban Forest Revolution
}

\author{
Anastasia Kucherova ${ }^{1}$, Hana Narvaez ${ }^{1, *}$ \\ ${ }^{1}$ Stefano Boeri Architetti, Via G. Donizetti 4 20122, Milan, Italy
}

\begin{abstract}
The tendency of the last 100 years shows the radical change of the proportion between urbanized areas and those dedicated to wild nature and agriculture. Whether we agree with it or not, cities are our future. Also it is confirmed by the annual reports of UNEP that cities are responsible for $75 \%$ of $\mathrm{CO}_{2}$ emissions. Among negative consequences of the uncontrolled urban sprawl on the ecology there are: greenhouse effect leading to global warming; increasingly growing number of people affected by respiratory diseases due to the smog; drastic reduction of the biodiversity. The environmental impact and the look of the city of the future is in the hands of the architects of today. At Stefano Boeri Architetti we are exploring one of the possible way of reducing the buildings' ecological footprint and improving the quality of air in cities. It is called "Vertical Foresting", an evolution of the revolutionary idea of bringing the trees to the sky, far beyond its first realization - it became a philosophy, a new lifestyle. But first of all, Vertical Forest is a big question mark, addressed to the global community, to the politicians and common people, asking each and every one living in our planet - what can you do for our common home?
\end{abstract}

\section{Introduction}

Stefano Boeri Architetti based in Milan, with offices in Shanghai and Tirana, (called Boeri Studio until 2008) is dedicated since 1993 to the research and practice of architecture and urbanism. Among the most known projects there are: the Vertical Forest in Milan, the General Local Plan of Tirana 2030 in Albania, the Villa Méditerranée in Marseille and the House of the Sea at La Maddalena.

Stefano Boeri Architetti has provided services for the architectural and urban design for over 20 years, especially on large scale projects and public space renewal. It develops projects and regeneration strategies in complex environments, outlining and supporting synergies between the various stakeholders, public and private entities. Counting on a staff of over 40 co-workers, in the design process SBA collaborates with a wide network of professionals, from engineering consultants and landscape architects, to social scientist specialist, to provide ad hoc solutions over a wide range of territorial and socio-economic contexts. This approach towards collaboration has allowed the studio to spread its practice and to pair with professionals such as Jeremy Rifkin, to develop a concept of urban planning for the third industrial revolution.

${ }^{*}$ Corresponding author: a.kucherova@stefanoboeriarchitetti.net 
Over the last years, the studio has developed a know-how in the new typology of the high rise building, integrating the trees and other plants with traditional construction materials. The first propotype of Vertical Forest, completed in 2014 in Milan, is a new model of sustainable residence in height, with two towers completely covered with more than 700 trees and 20.000 plants, The Vertical Forest has won numerous international awards, including the High Rise Building Award sponsored by the Museum of Architecture in Frankfurt in 2014 and in 2015 the CTBUH Award, as Best Tall Building Worldwide sponsored by the Council for Tall Building and Urban Habitat and the Illinois Institute of Technology both based in Chicago. After this first sustainable model of housing, the studio recently won a competition, in Lausanne, Switzerland, to further develop this model and build a new 117 meters tall residential tower, which will host more than 100 cedar trees and will be covered by shrubs and plants over an area of 3.000 sqm; this construction is scheduled to start in 2017. In the same time the third Vertical Forest is rising up in Nanjing, China, its completion is scheduled for 2018.

But the idea of urban forestation is now being developed to another level. The studio is working on several Forest cities around the world, starting from China, one of the most polluted countries. This practical experience, together with research activities both of our studio and other architects and environmentalists led us to formulate the basic principles of Urban Forest revolution.

\subsection{Why should we act immediately? Some considerations on the climate change}

"The Metropolis strives to reach a mythical point where the world is completely fabricated by man, so that it absolutely coincides with his desires" [14]. Nowadays the professional competences of an architect go far beyond just designing and building. It becomes more important than ever the ethics, the ability of team work in multidisciplinary groups, the ability of observing and analyzing the ever-changing conditions in which your building is going to exist, because the lifespan of a building is now sufficient to witness the drastically changing background. But, above all, not only as architects but as inhabitants of the Earth we should be sensitive to the problems of ecology and climate change which our planet is facing.
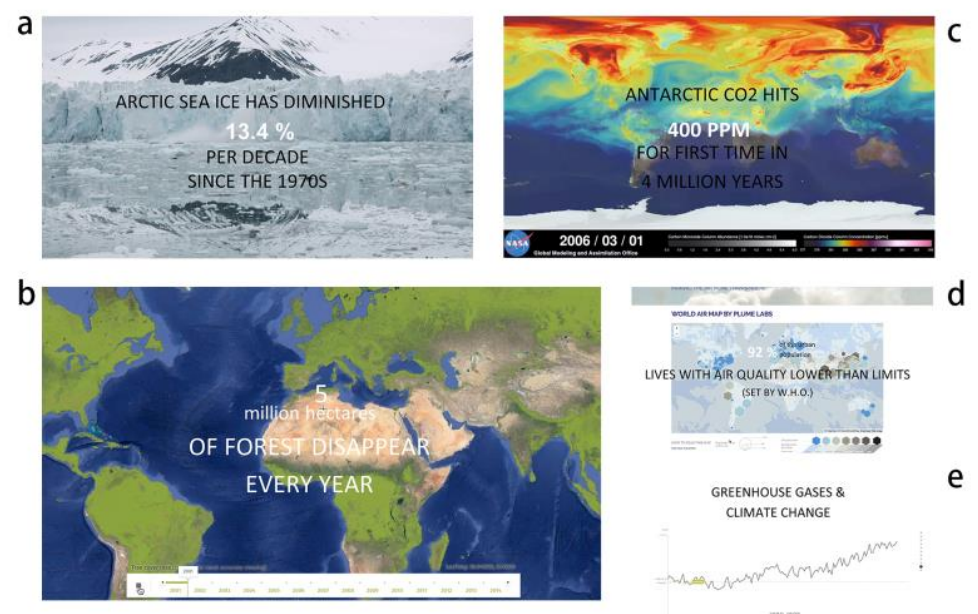

Fig. 1. Climate change and negative environmental effects of the cities: a - Arctic sea ice reduction; $\mathrm{b}$ - Air quality graphics in the cities of the world; $\mathrm{c}-$ Antarctic $\mathrm{CO}_{2}$ level change; $\mathrm{d}$ - Disappearance of the cities; $\mathrm{e}-$ Greenhouse gases and climate change. 
According to the estimations of UNEP cities are responsible for $75 \%$ of global $\mathrm{CO}_{2}$ emissions, vehicles and buildings are among the major contributors. This means that the architects and urban planners are more responsible than ever for the future of our cities. The environmental impact, the quality of life and the look of the city of the future is in the hands of the architects of today.

\section{Materials and Methods}

\subsection{Vertical Forest}

"A house for trees and birds, inhabited also by humans" Stefano Boeri [4]. The Bosco Verticale in Milan, Italy holds one of the most extensive living green facades ever realized. The combination of its sophisticated plant selection, the deployment of greenery in all orientations, the structural design to accommodate the plants, and the maintenance, safety and irrigation systems, represent one of the most innovative tall building projects in recent memory [6].

Vertical Forest is a model for a sustainable residential building, a project for metropolitan reforestation contributing to the regeneration of the environment and urban biodiversity without the implication of expanding the city upon the territory. It is a model of vertical densification of nature within the city that operates in relation to policies for reforestation and naturalization of large urban and metropolitan borders. The first example of the Vertical Forest consisting of two residential towers of 110 and $76 \mathrm{~m}$ height, was realized in the centre of Milan, on the edge of the Isola neighborhood, hosting 900 trees (each measuring 3,6 or 9 meters) and over 20,000 plants from a wide range of shrubs and floral plants distributed according to the sun exposure of the facade. On flat land, each Vertical Forest equals, in amount of trees, an area of $\mathbf{2 0 , 0 0 0}$ square meters of forest. In terms of urban densification, it is the equivalent of an area of a single family dwelling of nearly 75,000 sq.m. The vegetal system of the Vertical Forest contributes to the construction of a microclimate, produces humidity, absorbs $\mathrm{CO}_{2}$ and dust particles and produces oxygen.
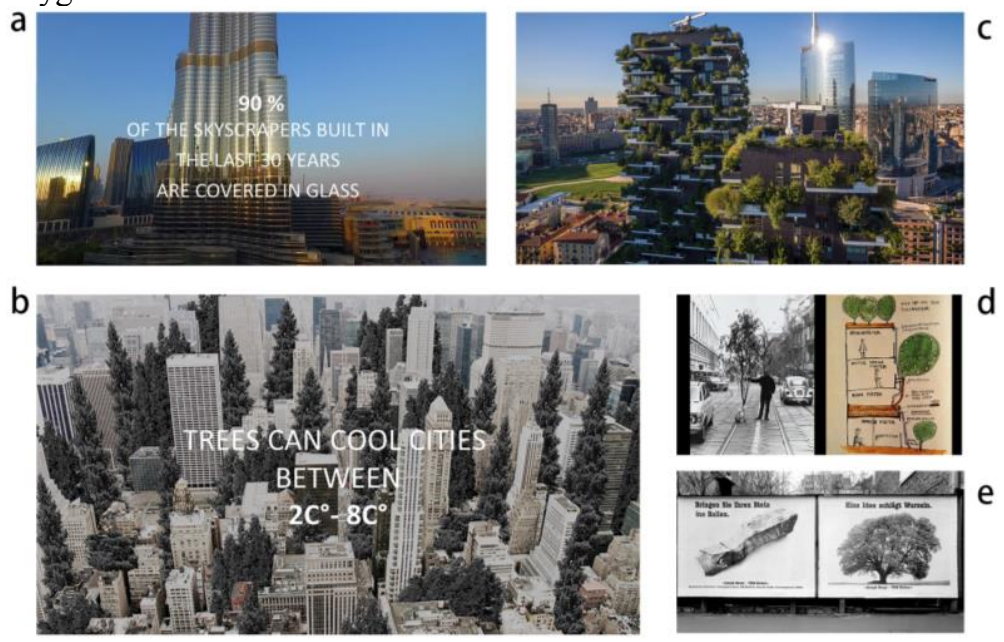

Fig. 2. Overview of the integration of the trees into built environment. Inspirations of Vertical Forest: $\mathrm{a}$ - Study of the mineralized urban surfaces (glass facades of the skyscrapers); $\mathrm{b}$ - Trees positive effects on heat reduction in urban environment; c - Vertical Forest introduction, Milan, Italy; d Friedensreich Hundertwasser in Milan in 1972, planting the trees on the balconies; e - Joseph Beuys artwork in Berlin, 1982. 


\subsubsection{Inspirations of Vertical Forest}

As any other architecture, Vertical Forest took shape under various influences, it grows on the soil of Italian and, in particular, Milanese architectural tradition, and sometimes, the inspiration comes from the most unexpected directions. "In 1972 I was 16 years old and I had no idea that travelling around the streets of my city, Milan, there was a bizarre character - the Austrian artist Friedensreich Hundertwasser - who while holding a tree was preaching the idea of a new style of architecture, built around the presence of trees in houses, courtyards and rooms.

In the middle of the streets with a small oak tree in his hand and just a few metres from the La Scala Opera House, Hundertwasser was making the case for organic architecture, based on a standard that governed the relationship between the number of humans and the number of trees in any space where people lived" [4]. Another strong impression that pushed Stefano Boeri to a revolutionary idea of bringing the trees to the sky, was the view of Dubai he was exploring in 2007 and its skyline composed entirely of glass and concrete skyscrapers. A triumph of artificial and mineral amidst the desert.

In 1982 in front of the Fridericianum Museum in Kassel the German artist Joseph Beuys built a triangle of 7,000 basalt stones, each of which was intended to be used for the planting of a tree. Anyone paying a sum of money, could "adopt" one of the seven thousand stones; the money raised would be used to plant an oak tree. So, day after day, the pile of stones diminished until it finally disappeared, and seven thousand new oak trees, each with one of the basalt stones at its base, appeared along the streets and avenues and in the squares of the city of Kassel [4].

\subsubsection{Living facades}

The real revolutionary element of the project - its trees- has influenced every part of the design. The vegetation is the outermost exterior element of the envelope and represents a filter between the interiors of the towers and the urban environment.

a
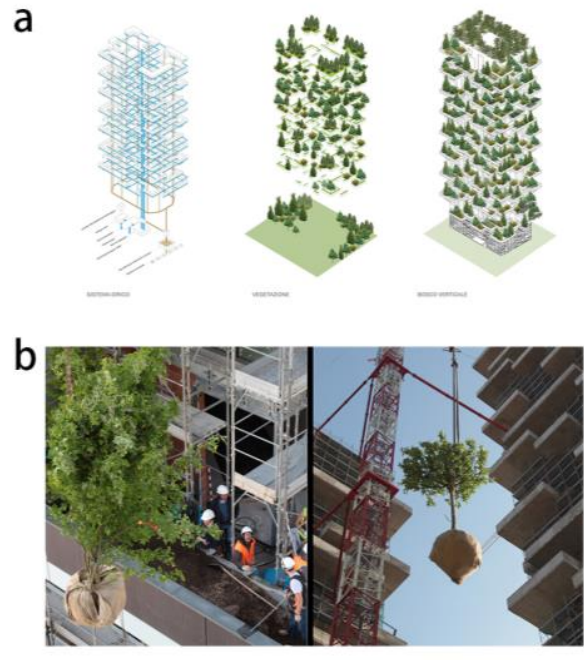
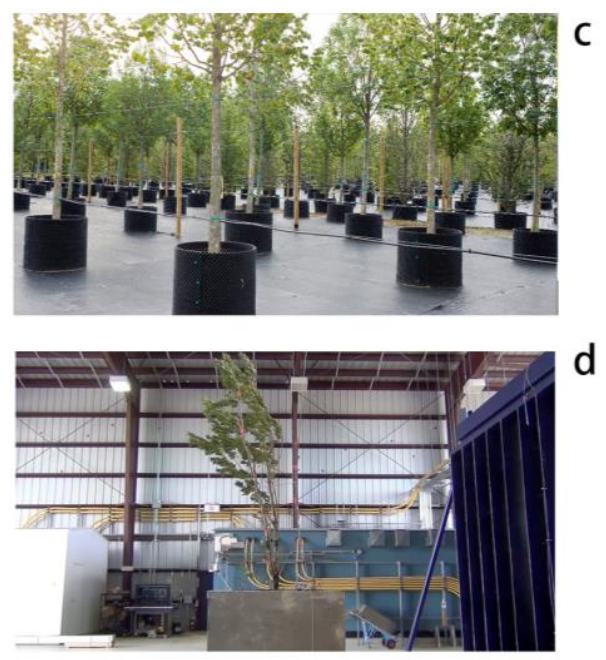

Fig. 3. Vertical Forest in Milan - first prototype of the new sustainable building typology: $\mathrm{a}$ - Irrigation system of the building and planting scheme; $\mathrm{b}$ - Planting of the trees on balconies; $\mathrm{c}$ - Trees in the nursery before being planted; $\mathrm{d}$ - Wind-resistance test of the tree species in Florida, USA. 
The water distribution network for irrigation is composed of three main elements: the principal network, which brings water from underground to the terraces; the control group in the plant containers, which regulates the water supply; and the drip line, which provides widespread distribution throughout the plant containers.

Pre-Cultivation: the trees were selected based on a consideration of the most advanced principles of pre-cultivation in nurseries. The trees, which are at least 15 years old, have precisely calibrated sizes (obtained thanks to a professional pruning) and are free of any "defects of shape," which means that they have a single trunk, the lateral branches do not compete with each other and are radial, well-spaced, symmetrical and lightly webbed.

\subsubsection{Manifesto}

- The Vertical Forest is an anti-sprawl project and a densification project to reduce urban expansion while increasing the quantity of green within the built city. A model that connects to the policies for reforestation and naturalization of the edges of large urban and metropolitan areas. Each tower of the Vertical Forest is the equivalent in height of an outdoor area of single-family houses and tree-lined gardens of approximately 50,000 square meters.

- The Vertical Forest is a forestation project which helps to demineralize urban surfaces. It is a project that helps to regenerate the environment by increasing urban biodiversity without implying an expansion of the city territory.

- The Vertical Forest sets a new urban standard in terms of balance between the human and the natural sphere. In a Vertical Forest, per each human there are 2 trees, 40 bushes, 8 shrubs, 30 birds and butterflies.

- The Vertical Forest increases biodiversity. The Vertical Forest favours the formation of an urban ecosystem - rocky and mixed - in which various types of green (tree, shrub, grass roof, green vertical connections between the arboreal nucleuses) create a sort of vertical environmental network that could also be colonized by wildlife rocky environment dwelling species (such as redstart or kestrel) and/or other species (such as chickadees, goldfinch, doves), but also by insects (such as diptera and some beetles, spiders, butterflies if there are corners of hedges and flowering lawns).

- The Vertical Forest is a project that reduces pollution and the environmental footprint. The vegetation on the Vertical Forest is designed in order to form a continuous vegetative filter between the interior and the exterior. Thanks to this filter of leaves on the facades, the Vertical Forest absorbs the urban pollutants produced by private vehicles in the urban environment.

- The Vertical Forest is a project of environmental sustainability. The irrigation of the plants is carried out to a large extent through the filtering and reuse of grey water produced from the building. The shielding produced by the arrangement of plants along the perimeter of each floor, promotes proper air-conditioning of apartments and reduces the consumption of electricity for air conditioning.

- The Vertical Forest is a living architecture. The green filter of the Vertical Forest is to be considered as a living façade of the building, therefore its maintenance needs to be controlled in a systematic way.

- The Vertical Forest increases the urban ecological culture. The service "cell" that will ensure the functionality and long-term maintenance of the vertical green can become a landmark for the city and the schools in the district as a parameter for urban ecosystems. Each "cell for maintenance of the vertical green" can in fact be used for the collection and dissemination of data needed to evaluate its ecological function over time (consensus of spaces and fluctuations in the colonization, etc.).

- The Vertical Forest is a new landmark in the urban landscape. The towers of the 
Vertical Forest do not offer only to those who live within an unusual perspective on the urban landscape from inside the apartment. By cyclically changing the skin according to the different type of plants and their different arrangement with respect to the solar thermal axis, the Vertical Forest also offers a changing panorama to the metropolitan crowd looking up.

- How to export Vertical Forest - adapt to local biodiversity. The Vertical Forest provides a model of combination between the urban and the natural world that can be adapted to different environmental conditions according to the local climatic zones. The vegetative and animal species populating the Vertical Forest in a cold climate will be different from the ones of a temperate or dry or tropical climate. Each climatic zone provides a set of local criteria to adapt the prototype to the local conditions.

\subsection{Evolution Of The High-Rise Forest Building}

\subsubsection{Tour Des Cedres}

"Les Terraces des Cedres" is not just a tower, nor simply a tall residential building. It is the prototype of a new dwelling model, a building that combines the comfort of the apartments, the wonderful view of the lake and nearby areas, with the vegetal world; especially with the various species of cedars that already inhabit the territory. A landmark that can be spotted from Lausanne northern border.

a
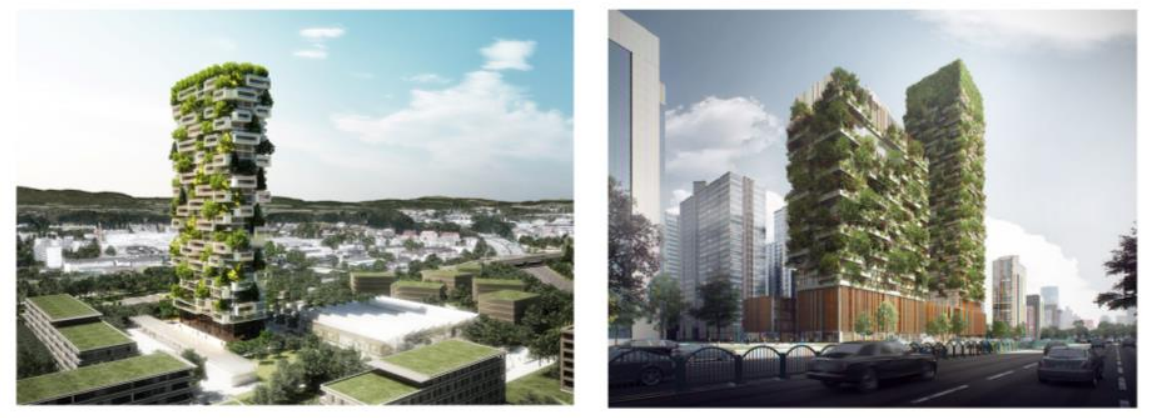

b

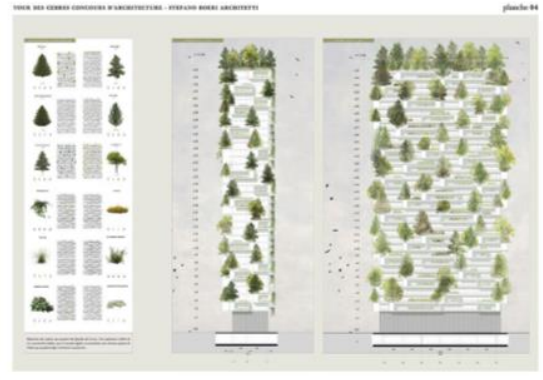

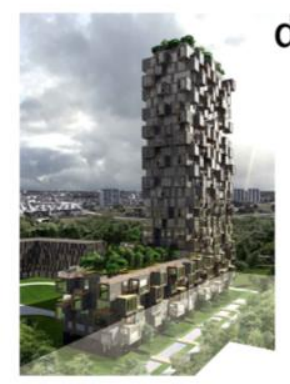

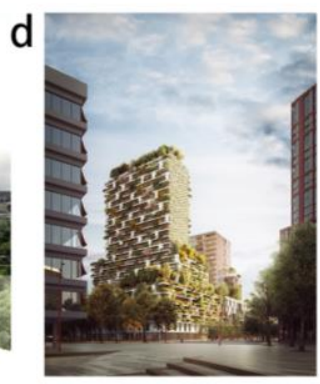

Fig. 4. Other high-rise buildings by Stefano Boeri Architetti in the world: a - Tower of cedars, Lausanne, Switzerland; b - Tower of cedars planting scheme and tree species used; $\mathrm{c}$ - Nanjing Towers, China; $\mathrm{d}$ - Urban tower, Antwerp, Belgium; e - Wonderwood, Utrecht, Netherlands.

The construction is a 117-meter-tall tower, with a rectangular plan of $52 \times 15.5$ meters, oriented north-south, composed of 36 floors that include a gym, offices, housing, and a restaurant. A structure that will host more than 100 trees (4 typologies of cedars) covered by shrubs and other plants over an area of 3,000 square meters, the volume of the tower is 
characterized by the presence of cantilever elements, of variable length that animate the facades and break the succession of levels. These prominent elements are cantilevered over $3 \mathrm{~m}$ mainly on the south facade and punctually on the east and west facades. Since the apartments loggias offer an extension of the outward space to fully enjoy the scenery. The residential tower is accompanied by a 5,000 square meters shopping mall.

The project establishes a clear separation between the residential, and the commercial spaces. The distinction of these main functions resulted in the drawing of three different buildings in close relationship with each other, connected by an open public space. The design of the plan integrating the three main buildings establishes a mass / void relationship where architecture and public open space are alternated. These spaces between buildings are living environments, full of activity and sociability. The choice to separate the tower building from the base, designed to accommodate public activities, favors the creation of urban relationships between the elements that shape the neighborhood, both in public and residential focal point.

The implantation of the tower site is the most developed of any public intervention, where new buildings are implanted along the main north-south directions. They redefine the view and the course of the whole intervention and the relationship between the site, the city, the highway, the ground.

\subsubsection{Nanjing Towers}

Nanjing Green Towers, promoted by Nanjing Yang Zi State-owned National Investment Group Co.ltd, will be the first Vertical Forest built in Asia. Along the facades, 600 tall trees, 500 medium-sized trees (for a total amount of 1,100 trees from 23 local species) and 2,500 cascading plants and shrubs will cover a 6,000 sqm area. A real vertical forest, contributing to regenerate local biodiversity, that will provide a 25 tons of $\mathrm{CO}_{2}$ absorption each year and will produce about $60 \mathrm{~kg}$ of Oxygen per day.

The taller tower, 200 metres high, crowned on the top by a green lantern, will host offices - from the $8^{\text {th }}$ floor to the $35^{\text {th }}$ - and it will include a museum, a green architecture school and a private club on the rooftop.

The second tower, 108 metres high, will provide a Hyatt hotel with 247 room of different sizes (from $35 \mathrm{sqm}$ to $150 \mathrm{sqm}$ ) and a swimming pool on the rooftop. The 20 metres high podium, will host commercial, recreational and educative functions, including multi-brands shops, a food market, restaurants, conference hall and exhibition spaces.

\subsubsection{Other Typologies of Sustainable Urban High-Rise Buildings}

The latest research of the studio is studying the possibilities of exporting the concept of green buildings in different contexts, in terms of climate and socio economical background. The towers developed for Antwerp (Belgium), Utrecht (Netherlands), Treviso (Northern Italy) represent different branches of evolution of urban high-rise building. In case of northern countries, the importance of sunlight entering the apartments is crucial. This requirement was both challenging and fortunate for the final design solution, since it encouraged us to push the limits of internal and external spaces, exploring the theme of terrace, balcony, under a completely different light.

The balconies in their northern version, from Switzerland to Netherlands are turned into extensions of the interior, bringing the residents closer than ever to the surrounding environment. In one way or another the high rise residential buildings explore and reinvent the border between private and public, between natural and artificial, between inside and outside. 


\section{Results}

\subsection{Towards the Forest City}

"When we dream alone it is only a dream, but when many dream together it is the beginning of a new reality". Friedensreich Hundertwasser

In 2014, the first two towers completely covered by trees and shrubs, equivalent to 20.000 sq $\mathrm{m}$ of real forest, have been completed in Milan. Since then this idea of densification of greenery in urban environment received scientific and political approval of its efficiency. Just two towers are able to absorb 19 tons of $\mathrm{CO}_{2}$ a year and to produce the comparable amount of oxygen. The presence of trees improves considerably the quality of living environment, both for the residents and other citizens, by humidifying the air, filtering the sun rays in summer, reducing the temperature inside the apartments by 2-3 grades. But how can this concept help to fight the air pollution on urban scale?

a

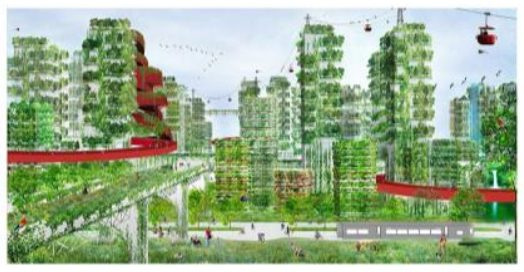

b

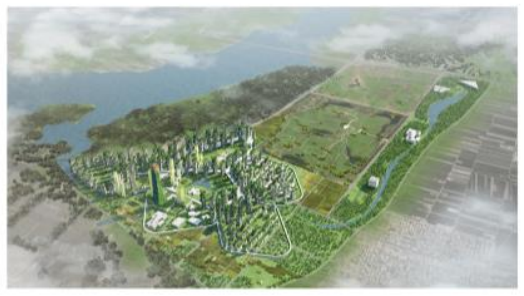

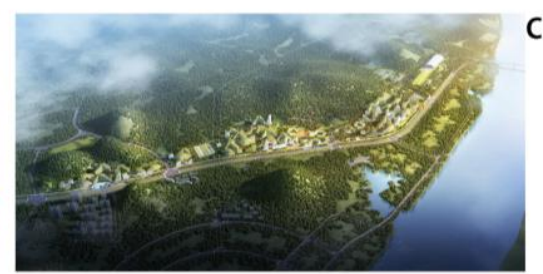

e

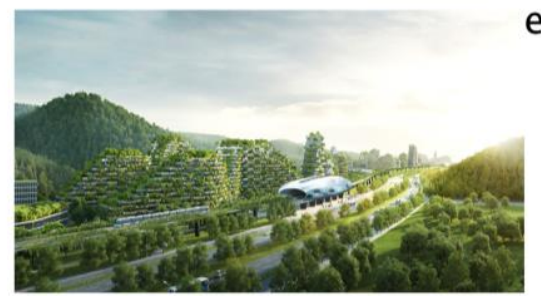

Fig.5. Forest cities of Stefano Boeri Architetti: a - Shijazhuang Forest City conceptual vision, China; b - Shijazhuang Forest City bird view; c - Liuzhou Forest City; d - Liuzhou green buildings and transport of the future

\subsubsection{Shijazhuang Forest city}

The answer, or rather the first hypothesis of expansion of the concept has been first developed for Shijazhuang. Shenzhen and other cities, are reaching a population of 60 million people. Shijiazhuang for its part, has a sad record: it is the city with the highest rate of air pollution in China. A pall of smog and soot rising only a few days a year. The Forest City in Shijiazhuang will be a new city for 100,000 inhabitants. A city of a new generation, capable of becoming a model of sustainable growth in a large country seeing, each year, 14 million farmers migrating to the cities.

ForestCityShijiazhuang $^{\circ}$ is:

- The prototype of a city composed by Vertical Forests. ForestCityShijiazhuang ${ }^{\odot}$ (FCS) is the prototype of a new generation of small, compact and green cities, composed by dozens of tall and middle size buildings - the so called "VerticalForests"all surrounded by the leaves of trees (ranging from 3-9 meters in hight), shrubs and flowering plants. Every VF grafts the equivalent of thousands of 20.000 square meters (2 ha) of a real forest. 
- An urban ecosystem. ForestCityShijiazhuang ${ }^{\odot}$ is an urban ecosystems which hosts 100,000 inhabitants and occupies a land of 225 hectares. ForestCityShijiazhuang $^{\odot}$ is composed by 5 districts and one central Park (carpel). Every district (petal) is hosting ca. 20,000 inhabitants. Every Petali is a mix-use social environment, with residential housings, offices, retails, malls, public spaces and gardens. The central Park (carpel) is the place for the main Public Facilites of FCS: the Hospital, the School, the Cultural Activities.

- An anti-sprawl device. Every Forest City will concentrate in a vertical dimension and within a perimeter of 1,5 for 1,5 square kilometers (225 hectares) - the urban volumes that normally are hosted in 25 hectares of land.

- A sustainable city, with low energy consumption. The vegetative filter on the buildings balconies creates a reduction - in the difference between the outside and inside temperature - of about 3 degrees.

- An absorber of $\mathrm{CO}_{2}$ and the dust of urban pollution. FCS cleans the air. The vegetation within FCS is designed in such a way as to form a continuous green filter between inside and outside of inhabited areas, able to absorb the fine particles produced by urban traffic, to produce oxygen, to absorb $\mathrm{CO}_{2}$, and to shield the balconies and interiors from very high pollution of Chinese cities.

- A multiplier of biodiversity of the living species. FCS will be the home of hundreds of different spices of plant life, including trees, shrubs and perennials. FCS will host many spices of birds and domestic animals.

- An ever-changing urban landmark. Thanks to the variety of plant spices housed along the balconies - and in the presence of deciduous trees -, FCS will change its skin and the color composition of its leaving facades, according to changing seasons and weather conditions.

- The basic element of a new model of urbanization in China. FCS is a model of urbanization and the basic element for a large number of settlement combinations. Different FC could be assembled in a cluster or along a line, creating a major conurbation, but always respecting the maintenance of the standard established in FCS: for 225 hectares of a city in 25,000 hectares of a green (agricultural, natural, sport) permeable land.

Urban Forest Revolution is just one of the measures that must be applied within a complex strategy of environmental protection. Globally speaking, it integrates the 5 pillars of the Third Industrial Revolution formulated by Jeremy Rifkin. "The five pillars of the Third Industrial Revolution are (1) shifting to renewable energy; (2) transforming the building stock of every continent into micro-power plants to collect renewable energies on site; (3) deploying hydrogen and other storage technologies in every building and throughout the infrastructure to store intermittent energies; (4) using Internet technology to transform the power grid of every continent into an energy-sharing intergrid that acts just like the Internet (when millions of buildings are generating a small amount of energy locally, on site, they can sell surplus back to the grid and share electricity with their continental neighbors); and (5) transitioning the transport fleet to electric plug-in and fuel cell vehicles that can buy and sell electricity on a smart, continental, interactive power grid" [1].

\subsubsection{Liuzhou Forest City}

Liuzhou has a unique landscape of karst, the design inspiration for the design blueprint and for building integration into the local landscape comes from the characteristics of this mountain soil. Vertical forest technology will help us to achieve this vision. Liuzhou City, located in the northeastern part of the Guangxi Zhuang Autonomous Region, is a unique 
landscape of the historical and cultural city. In recent years, the urban construction of Liuzhou has been accelerated, and the urban spatial pattern of "one city, two cities" has been gradually forged with the Lianhua Mountain Scenic Area as the "green heart" and the main city and the Liudong New Area.

This living settlement follows the Vertical Forest and Forest City ideas introduced both in horizontal and vertical distribution of green facade surfaces. The living environment creates an ideal space for symbiosis between Man and Nature. Function: purifying city air, absorbing Carbon dioxide and dust particles, and producing oxygen; blocking radiation and noise; creating more living space also for birds, insects, and small animals.

Structural design: planting suitable local tree species along the outer wall, building a watering system, using recycled water to maintain plant growth, and producing wind energy and solar energy to increase energy self-sufficiency.

\section{Conclusions}

"Generations of human beings were transformed into machines in the relentless pursuit of material wealth: We lived to work" [1].

Building always more and more, conquering the soil from nature has been the objective of architecture in the same way it worked for the world in general. But nature is warning us that we have to reconsider the long-term strategy. It is no longer a question of respect of our habitat, it's a matter of survival of mankind and the planet. That's why sustainable strategies are nowadays acquiring the same importance for architecture as structural design and engineering. As J. Rifkin says, the buildings must be converted from the major polluters into natural filters, from principal energy consumers into energy factories. Realization of the first Vertical Forest established a new era in the relationship between mankind and other species.

Vertical ForestING - is a worldwide trend, generated by the first Vertical Forest built by Boeri Studio in Milan, in 2014. When Stefano Boeri came up with the idea of giving back to nature the space we are taking from it with continuous urban sprawl, he conceived Bosco Verticale as a prototype of the skyscrapers of the future. Today we see that the Future is now. Every day architects all around the world rethink and reinterpret the idea of the Trees in the sky. Each of these attempts is extremely important for the future of architecture and the Future of our planet, because the single thought can have certain impact, but thousands of thoughts can change the world. Slowing down the climate changes, reducing $\mathrm{CO}_{2}$ emissions, making our living sustainable and in harmony with nature.

\section{References}

1. J. Rifkin, The Third Industrial Revolution: How Lateral Power Is Transforming Energy, the Economy, and the World (2011)

2. S. Boeri, Biomilano. Glossary of ideas for a metropolis based around bio-diversity (Corraini edizioni, 2011)

3. S. Boeri, La città scritta (Quodlibet, 2016)

4. S. Boeri, A Vertical Forest. Instructions booklet for the prototype of a forest city (Corraini edizioni, 2015)

5. Harry Rand, Hundertwasser (Taschen, 2007)

6. Elena Giacomello, Massimo Valagussa, Vertical Greenery. Evaluating the High-Rise Vegetation of the Bosco Verticale (CTBUH Research Report, 2015)

7. I. Calvino, Il Barone Rampante, Einaudi (1957) 
8. E. Thomas, R. Jalonen, J. Loo, D. Boshier, L. Gallo, St. Cavers, S. Bordács, P. Smith, M. Bozzano, Genetic Considerations in ecosystem restoration using native tree species, Forest Ecology and Management, 333, 66-75 (2014)

9. Peter Droege, La città rinnovabile (Edizioni Ambiente, 2008)

10. Richard Register, Ecocities. Rebuilding cities in Balance with Nature (2006)

11. E. Howard, A Peaceful path to Real Reform (1898)

12. Maurizio Corrado, Vegetecture (2011)

13. http://greenevolution.ru (last accessed 2017.04.27)

14. R. Koolhaas, Delirious New York (2001) 